\title{
marges Marges
}

revue d'art contemporain Revue d'art contemporain

$03 \mid 2004$

La place de l'image dans le monde contemporain

\section{Exposition, «L'intime, le collectionneur derrière la porte »}

La Maison rouge - fondation Antoine de Galbert, 5 juin-26 septembre 2004.

Jérôme Glicenstein

\section{OpenEdition}

Journals

Édition électronique

URL : http://journals.openedition.org/marges/780

DOI : $10.4000 /$ marges.780

ISSN : 2416-8742

Éditeur

Presses universitaires de Vincennes

Édition imprimée

Date de publication : 15 novembre 2004

Pagination : $110-11$

ISBN : 978-2-84292-247-4

ISSN : $1767-7114$

Référence électronique

Jérôme Glicenstein, «Exposition, «L'intime, le collectionneur derrière la porte » », Marges [En ligne], 03 2004, mis en ligne le 06 août 2014, consulté le 22 septembre 2020. URL : http://

journals.openedition.org/marges/780; DOI : https://doi.org/10.4000/marges.780

Ce document a été généré automatiquement le 22 septembre 2020.

(c) Presses universitaires de Vincennes 


\section{Exposition, « L'intime, le collectionneur derrière la porte »}

La Maison rouge - fondation Antoine de Galbert, 5 juin-26 septembre 2004.

Jérôme Glicenstein

\section{RÉFÉRENCE}

Exposition, «L'intime, le collectionneur derrière la porte », La Maison rouge fondation Antoine de Galbert, 5 juin-26 septembre 2004.

1 L'inauguration de la "Maison rouge » au mois de juin 2004 a constitué un événement parisien dont la presse s'est fait largement l'écho, au point où l'on pourrait penser qu'il ne s'agissait là que de l'un des nombreux moments qui jalonnent banalement la vie paisible du monde de l'art français (même s'il n'est pas commun de voir s'ouvrir en France des fondations privées consacrées à l'art contemporain). Pourtant, il s'agissait avec l'exposition inaugurale, "L'intime, le collectionneur derrière la porte ", d'une expérience assez inédite, puisque selon les mots mêmes d'Antoine de Galbert, " "L'intime" traite davantage des attitudes des collectionneurs que de leurs propres collections ».

2 Et de fait, cette exposition troublait dès le premier abord, lorsqu'on se trouvait confronté à une série de reconstitutions d'intérieurs, qu'on ne pouvait le plus souvent qu'observer qu'à la dérobée, dans l'entrebâillement d'une porte ou par la fenêtre. Outre ce type de dispositif curieux qui transformait le visiteur en une sorte de voyeur, l'effet était redoublé par le sentiment d'une «impureté » de l'expérience esthétique ; les œuvres d'art étant à la fois mélangées entre elles de manière presque incohérente et placées vis-à-vis d'objets quotidiens qui ne les mettaient pas particulièrement en valeur.

3 Ce que donnait à voir cette exposition n'était de fait pas tant un ensemble d'œuvres d'art - ni même les personnes qui les collectionnent -, mais autre chose : un certain 
type de « relation esthétique quotidienne ». On était confronté à des œuvres d'art, non seulement dans des espaces qui n'étaient pas les espaces «idéalistes » et «décontextualisants » du musée, mais qui plus est, qui présentaient tous les attributs d'appartements bourgeois où les œuvres d'art sont "perdues parmi les choses » (et deviennent elle-mêmes « choses »).

Évidemment, ce type d'expérience d'exposition n'est pas le premier et il y a eu des exemples similaires célèbres. On se souvient de l'exposition "Chambres d'amis » réalisée par Jan Hoet dans les appartements d'une cinquantaine de collectionneurs de Gand en 1986, ou encore de "Passions privées ", une présentation d'œuvres provenant de quatre-vingt-douze collections privées, au Musée d'art moderne de la ville de Paris en 1996. Mais ces deux expositions procédaient de formules encore assez « convenues ». À «Chambres d'amis » il s'agissait principalement d'œuvres installées in situ, chez les collectionneurs, par des artistes choisis en concertation avec le directeur du musée. Les œuvres permettaient en quelque sorte d'élargir symboliquement les limites physiques du musée de Gand.

5 Dans le cas de "Passions privées » il s'agissait à l'inverse, pour les commissaires du MAMVP, de choisir des œuvres chez les collectionneurs pour les déplacer avenue du Président Wilson. Une opération qui si elle avait au départ suscité l'adhésion quasiunanime des principaux intéressés (ne serait-ce qu'en raison de la plus-value symbolique et monétaire envisageable à la suite d'une présentation publique), avait été suivie d'une vague de protestations qui n'était pas due exclusivement aux visites consécutives des services du fisc, mais aussi à l'idée que le musée se serait «servi » des collectionneurs pour renforcer la légitimité de ses choix. Et de fait, les œuvres choisies ne l'avaient pas tant été en fonction des parti pris singuliers des différents collectionneurs, que d'une sorte «d'histoire officielle» énoncée par le musée et reflétée dans les choix des particuliers. Au point où plus d'un collectionneur s'était plaint de n'avoir pu présenter telle ou telle œuvre qui lui tenait particulièrement à cœur.

6 Toute autre est la posture adoptée à la Maison rouge, puisqu'il s'agissait de reconstituer aussi fidèlement que possible les conditions selon lesquelles les œuvres d'art sont «utilisées » par leurs propriétaires. De ce point de vue, le plus intéressant, ce n'étaient pas tant les "accumulations d'œuvres" - un peu prévisibles - ou la "cohérence stylistique » entre les catégories d'objets collectionnés et le cadre de vie de telle ou telle personne, mais peut-être au contraire des " petits écarts » perceptibles ici ou là entre la qualité de tel ou tel objet et la banalité des traces de la vie quotidienne (journaux, livres, coupe-papier, chaîne hi-fi, cendrier, moquette, meubles un peu usés, etc.). Cet écart était troublant et presque rebutant, puisqu'il nous ramenait à une sorte de «matérialité » : à un " effet de réel ». La sensation ne venait pas simplement de l'idée qu'on était un peu "voyeur » en épiant chez les gens, que de l'idée que l'on était confronté à une sorte de miroir où nous nous serions un peu retrouvés, avec nos incohérences et la complexité de nos vies et la poussière enveloppante du quotidien. 